AWEJ for Translation \& Literary Studies, Volume2, Number 1, February 2018

Pp.4-25 DOI: http://dx.doi.org/10.24093/awejtls/vol2no1.1

\title{
The Cognitive Stylistic Translator
}

\author{
Ghazala, H. S. \\ Department of English, College of Social Sciences \\ Umm Al-Qura University, Makkah Al-Mukarramah, Saudi Arabia
}

\begin{abstract}
Translation theory is never dogmatized. It is a dynamic and ever changing process. It is expected to respond positively to new developments in the studies of language and style. Cognitive stylistics is one of the major new developments in the study of style. It is based on viewing and analyzing style as a cognitive process of mind that goes beyond the boundaries of surface meaning to unearth the truth behind it. This process draws heavily on the cultural, social, political, and ideological conceptualization of style and meaning. The cognitive process of translating is claimed here to have been influenced by contemporary cognitive stylistic approaches that view meaning as the product of style as mind. This paper investigates the updated cognitive properties, responsibilities, practices and other characteristics to be assumed by the cognitive stylistic translator in the light of these new cognitive approaches to meaning and style in terms of mind. Accordingly, the cognitive translator is urged to approach the translation of the texts' styles and meaning cognitively to respond creatively to the explorations of cognitive stylistic theory and applications. This will make them uncover buried truths and meanings that cannot be discovered otherwise. Toward the end of the paper, a relativity theory of cognitive stylistic translation is put forward. This theory is flexible enough to respond effectively to all cognitive potentials of meaning and style. Further, it accommodates more than one cognitive version of translation by means of applying two suggested methods of translation to the same text: direct (or style-based); and indirect (non-style-based). This means that more freedom of choice of possible versions of translation is available to translators and readers to pick up.
\end{abstract}

Keywords: cognitive, stylistic, style, translator, translation theory, translation method, style-based translation

Cite as: Ghazala, H. S. (2018). The Cognitive Stylistic Translator. Arab World English Journal for Translation \& Literary Studies, 2 (1). DOI: http://dx.doi.org/10.24093/awejtls/vol2no1.1 